\title{
Correction to: High-solids thermophilic anaerobic digestion of sewage sludge: effect of ammonia concentration
}

\author{
M. Takashima ${ }^{1} \cdot$ J. Yaguchi ${ }^{2}$
}

Published online: 10 November 2020

๑) Springer Japan KK, part of Springer Nature 2020

\section{Correction to: \\ Journal of Material Cycles and Waste Management https://doi.org/10.1007/s10163-020-01117-z}

In the original publication of the article, the Eq. 4 has been wrongly published. The correct Eq. 4 is given in this correction.

The original article has been corrected.

Recovery against $\mathrm{TN}$ in ifluent sludge $(\%)=\frac{\mathrm{TAN}_{\text {rec,mass }}}{\mathrm{TN}_{\mathrm{inf}, \text { mass }}} \times 100$.

Publisher's Note Springer Nature remains neutral with regard to jurisdictional claims in published maps and institutional affiliations.

The original article can be found online at https://doi.org/10.1007/ s10163-020-01117-z.

M. Takashima takasima@fukui-ut.ac.jp

1 Department of Architecture and Civil Engineering, Fukui University of Technology, 3-6-1 Gakuen, Fukui 910-8505, Japan

2 Department of Industrial Systems Engineering, National Institute of Technology, Hachinohe College, 16-1 Uwanotai, Tamonoki, Hachinohe 039-1192, Japan 